\title{
Bernard Comment. Le XIXe siècle des panoramas. Paris: Adam Biro, 1993
}

Resenha por Heloisa Barbuy

Museu Paulista/Universidade de São Paulo

Vivemos, nestes últimos anos do século XX, profundas mudanças em nossas noções de realidade, aceleradas pela informática. Fala-se em realidade virtual, expressão que encerraria, em si mesma, um paradoxo.

Não há dúvida de que o sentido visual prepondera, cada vez mais, sobre os outros quatro; ou os conduz. Cada vez mais é com o sentido visual, entrelaçado a mecanismos intelectuais de abstração que se atua e é através dele que se operam as mais desnorteadoras transformações.

Erra, porém, quem insistir em situar em nosso tempo e na tecnologia atual as origens do fenômeno. Elas podem ser localizadas mais para trás, nos últimos anos do século XVIII, no bojo da sociedade industrial. $\mathrm{O}$ que vivemos agora é talvez o final de um processo, a intensificação de uma tendência - ou de uma busca - cujos primeiros e largos passos foram dados durante o século $X I X$. O verdadeiro momento de ruptura não é, provavelmente, o final do século XX mas a virada do século XVIII para o XIX.

Ao fazer estas afirmações estamos nos referindo a uma revolução técnico-óptica que se deu na primeira metade do século XIX e que foi estudada por Jonnathan Crary (1990), da Universidade de Columbia. Segundo este autor, baseado em Foucault, durante a primeira metade do século XIX (mais especialmente entre 1820 e 1840), com o desenvolvimento da sociedade industrial, com a crescente mecanização e as rígidas organizações fabris, iniciam-se pesquisas na área de Fisiologia, buscando-se um melhor conhecimento do corpo humano e de suas possibilidades de rendimento. 
Uma das áreas que mais se desenvolve é a da óptica. Para o estudo do olho humano cria-se uma série de pequenos aparelhos ópticos, tais como o estereoscópio ou o zootrópio, que mais tarde foram difundidos como brinquedos, voltados para o divertimento. Todos eles trazem em si um jogo de relações entre ilusão e realidade; entre aquilo que é apreendido opticamente e uma objetividade independente do observador. Começa um processo de mudança nas noções de realidade e começa, também, o processo através do qual esta noção passa a ter como referência básica o sentido visual. Os fenômenos visuais subjetivos, antes tratados como "ilusões visuais", passam a ser referenciados como "verdades ópticas" (cf. Crary 1990: 97). Toda sorte de mecanismos/truques/técnicas que propiciasse este tipo de experiência ganha relevância. Aos inúmeros inventos ópticos de então, soma-se, ainda, a "redescoberta" de inventos anteriores, como as sombras chinesas ou a lanterna mágica, que se tornam uma espécie de moda (sobre as lanternas mágicas, ver Le Men, 1995).

Desde os últimos anos do século XVIII e durante todo o século XIX, ao lado dos pequenos instrumentos/brinquedos ópticos de uso individual, algumas invenções de maior porte, destinadas a apresentações coletivas, tornam-se foros de diversão pública. Trazem nomes diversos, tais como cosmoramas, neoramas, dioramas, panoramas... É o tempo dos "ramas", conforme trecho de Balzac, freqüentemente citado por autores que estudam esses inventos ópticos:

"La récente invention du Diorama, qui portait l'illusion d'optique à un plus haut degré que dans les Panoramas, avait amené dans quelques ateliers de peinture la plaisanterie de parler en rama, espèce de charge qu'un jeune peintre, habitué de la pension Vauquer, y avait inoculée.

(Honoré de Balzac, Père Goriot)

Não por acaso, o sufixo "orama", de origem grega, significa "ver". Trata-se, de fato, da plena ocorrência de uma revolução visual sem precedentes e que representa transformações profundas nas formas de apreensão - e de concepção - da realidade pelo homem. Um desses inventos é o panorama, patenteado pelo escocês Robert Barker, em 1787. Num edifício circular, especialmente construído para esse fim (rotunda), uma tela com altura de vários metros era instalada em 360 graus, dando a volta, internamente, no edifício. Ao centro, uma plataforma, onde se postava o observador. (A partir de 1870 é estabelecido um tamanho standard - 15 metros de altura por 220 metros de comprimento -, o que visa facilitar a distribuição das telas pelo circuito de rotundas existentes - cf. Comment 1993: 38). Este observador era alguém que pagava para entrar e assistir ao espetáculo, ao lado de outras tantas pessoas. Constituía-se, assim, uma platéia de espectadores. $O$ cerne do espetáculo consistia nos efeitos ópticos provocados pela luz natural fou artificial, conforme o casol, que atravessava a tela. As linhas de delimitação superior e inferior, na junção da tela com o edifício, eram mascaradas, para dar a ilusão de uma paisagem ou cena real. Este era o objetivo. A confusão entre ilusão e realidade é a base do espetáculo e a patente que o registrou, em 1787, assim o definiu: 


\begin{abstract}
"Minha invenção, que denomino 'la nature à coup d'oeil' destina-se, por meio de certos desenhos e de certas pinturas, e de uma disposição conveniente do todo, a criar a perspectiva plena e inteira de um país qualquer ou de sua situação, tal como se apresenta a um observador que gira à sua volta".

IRobert Barker, trecho da especificação da patente que the foi concedida, em 19 de junho de 1787, pela invenção do panorama. O original encontra-se no Repertory of Arts and Manufactures, Londres).
\end{abstract}

Neste final do século XX, provavelmente pela própria inquietação com que se vivem as novas relações entre ilusão e realidade, permeadas pela tecnologia, redescobre-se o fenômeno dos panoramas, objeto de várias exposições e publicações nas últimas décadas.

O alemão Heinz Buddemeier (1970) é o precursor desta leva de estudos mais recentes. Durante as décadas de 1980 e 90 muito se tem trabalhado em torno do assunto "panorama" e entre as obras publicadas estão a do alemão Stephan Oettermann (1980) e as da italiana Silvia Bordini (1981 e 1984), além de um colóquio realizado em Lucerna e publicado sob o título Das Panorama (1985), do catálogo organizado em Londres por Ralph Hyde (1988) para a exposição Panoramania: the art and entertainment of "allembracing" view, apresentada na Barbican Art Gallery e daquele organizado em Bonn (1993) para a exposição Sehsucht - das Panorama als Massenunterhaltung des 19. Jahrhunderts, realizada na Kunst-undAusstellungshalle. Todas estas obras têm o objetivo de mostrar um "panorama" dos panoramas e das problemáticas que envolvem. Cumpre mencionar, também, o catálogo da exposição Panoramas - photographies 1850-1950 (1989), com fotografias da coleção Bonnemaison, realizada em Arles, no Espaço Van Gogh, durante o XX Encontro Internacional de Fotografia. O objeto principal da exposição era a fotografia panorâmica e o texto do catálogo aponta seu vínculo intrínseco com os panoramas de que estamos tratando. Este vínculo foi tratado também no catálogo de Bonn acima citado, tanto no que se refere às vistas panorâmicas como às técnicas precursoras da fotografia (vedute, câmara escura, lanterna mágica, etc.). E Bernard Comment perfila, ainda, dentro do assunto, o catálogo dirigido por Odile Nouvel-Kammer, relativo a uma exposição sobre papéis de parede panorâmicos, organizada no Museu de Artes Decorativas de Paris.

Os panoramas introduziram-se e impuseram-se no quotidiano de grandes capitais pelo mundo afora, muito mais por seu caráter de espetáculo público/empreendimento comercial do que na condição de obras de arte. Os sistemas sócio-urbanos, relacionados aos aspectos comerciais e de afluência de público dos panoramas de Paris são analisados por Robichon num artigo publicado na revista Le mouvement social (1985); como pintura, eram considerados sempre obras menores e sobre isso Robichon (1982) desenvolve parte de sua tese de Doutoramento de 3o. ciclo. Citando Quatremère de Quincy, mostra como o panorama era desconsiderado pelos eruditos, por lançar mão de "artifícios" em lugar da "imitação realmente artística", tratandose, assim, de "ilusão ilegítima", pretendendo enganar e não proporcionar a visão de um objeto real através de um objeto artístico. O panorama acaba por 
ser considerado como produção industrial (cf. Robichon 1982: 269-285 e, também, Comment 1993: 59-611.

François Robichon é, provavelmente, o maior conhecedor do tema dos panoramas na França. Embora sua tese de Doutoramento não tenha sido editada, publicou alguns artigos bastante importantes a respeito e escreveu 0 capítulo sobre os panoramas na França, no catálogo da exposição da Kunst-undAusstellungshalle de Bonn. Curiosamente, entretanto, o primeiro livro a respeito do assunto publicado em língua francesa não é de sua autoria, mas do suíço radicado na França, Bernard Comment, intitulado Le XIXe siècle des panoramas.

Há grande mérito em preencher esta lacuna quando se sabe que, no século XIX, Paris - como de tantas outras coisas - foi a capital dos panoramas. Embora o livro de Comment não trate especialmente dos panoramas na França e em sua primeira parte - "Données historiques" - apresente um histórico dos panoramas na Inglaterra, França, Alemanha, Suiça e Estados Unidos, na segunda parte - "Questions théoriques" -, o autor apoia-se, para suas análises, mais no caso francês (seguido pelo inglês), do que nos outros, o que, aliás, corresponde ao próprio peso que tiveram os panoramas nestes países. A publicação traz, ainda, vinte e oito ilustrações (em preto e branco), o que é de considerável valia numa obra que pretende explicar um espetáculo visual por excelência. As figuras formam uma seleção interessante, capaz de cobrir diferentes questões tratadas ao longo do texto, como a transformação da imagem, no diorama, pelos efeitos de luz que fazem com que uma paisagem passe de diurna a noturna (figura 13, citada na p. 31) e da composição que conjuga a "visão de perto" (com primeiros planos que buscam proximidade com o observadorl com a "visão de longe", substifuindo o próprio movimento do observador que, diante de uma tela "comum", se aproximaria e se distanciaria, sucessivamente, para ter esse tipo de efeito (figura 7, citada na p. 16 e na $\mathrm{p}$. 77). Comment faz um uso analíico das imagens bastante apropriado mas se 0 interesse maior do leitor for pela iconografia relativa aos panoramas, será mais indicado que procure o catálogo da exposição de Bonn (1993), citado acima, que dificilmente será superado neste sentido.

Quanto aos dados históricos, Comment apresenta um quadro geral, recheado de informações importantes, que podem ser a ponta do fio para o leitor que quiser começar a conhecer o assunto mas a obra não pode ser considerada como uma "enciclopédia dos panoramas". Mesmo porque, apesar de rica neste sentido, não pretende se tornar um livro para consultas e sim para reflexão. Tanto que em sua nota número 1, remete o leitor à obra de Oettermann (1980), indicando que contém "un historique très complet et documenté sur les panoramas, qui constitue la plus sûre référence à ce jour, hormis quelques rares imprécisions dans le domaine français, qui sont ici rectifiés quand il est besoin" (p. 8). Observe-se, ainda, que a publicação do livro de Comment foi concomitante com a do catálogo de Bonn e por isto ele não poderia ter citado este último.

Ainda quanto à parte da obra referente aos dados históricos, cumpre fazer notar alguns pontos: o primeiro deles é o fato de Comment não ter sequer mencionado a historieta segundo a qual a origem do panorama estaria na 
experiência de seu inventor Robert Barker, que, preso por dívidas na cadeia de Edimburgo, ao tentar ler, sob a luz que entrava por um respiradouro, no alto da cela, percebeu interessantes efeitos ópticos que se produziam quando esta atravessava o papel. Ao sair da prisão, teria patenteado a idéia, aplicada à pintura. Tendo em vista o grande número de autores que recontou esta história, no século XIX e no XX, Comment deveria ter se dado ao trabalho de comentála. Se não procede, teria sido interessante que demonstrasse por que, ao invés de apenas silenciar a respeito, abrindo seu livro com um relato igualmente difícil de provar:

"Se promenant un jour de 1787 sur Carlton Hill, avec Édimbourg à ses pieds, Robert Barker (1739-1806), portraitiste et miniaturiste autodidacte, eut brusquement l'idée d'une représentation circulaire à même de rendre compte dans sa totalité du magnifique paysage qu'il pouvait contempler: le panorama était né, qui assurera sa fortune et sa gloire" (p. 13).

Bordini (1984: 30) conta a mesma versão que Comment, com mais detalhes, explicando que Barker, na colina de Edimburgo:

"intui la possibilità di riprodurre in un unico quadro l'intera veduta che appariva dalla cima del colle, adottando uno speciale procedimento di ripresa dal vero. Si doveva collocare un telaio quadrato, un tipo semplicissimo di prospettografo, in un luogo determinato, girarlo progressivamente per inquadrare via via lo scenario, ed eseguire una ripresa completa e prospetticamente esatta di tutto quanto era visibile nel telaio stesso, in una serie di singole porzioni contigue..."

A diferença entre localizar a origem do panorama na idéia da circularidade da pintura ou na idéia da luminosidade que atravessa a tela, provocando efeitos ópticos, talvez coincida com o interesse principal do autor, conforme seja a pintura em si e as técnicas correspondentes para a interpretação de uma paisagem ou as técnicas destinadas a aumentar, sensorialmente, a ilusão de realidade da paisagem apresentada. No caso de Silvia Bordini, está claro qual o interesse principal, indicado desde o início pelo próprio subtítulo de sua obra, la visione totale nella pittura del XIX secolo. Já em Comment, revela-se uma forte preocupação com as questões relativas à ilusão, à imitação e à experiência óptica mas o fio que conduz sua análise também é, sem dúvida, o da história da pintura.

$\mathrm{Na}$ verdade os panoramas sempre foram estudados dentro do campo da História da Arte e por isto utiliza-se, principalmente, o instrumental teórico relativo à pintura, que é um dos componentes do panorama e, subsidiariamente, os relativos à arquitetura. François Robichon também fez sua tese de Doutoramento de 3o. ciclo (1982) em História da Arte mas tendeu nitidamente para a inserção do fenômeno num campo mais amplo da História da Cultura. $\bigcirc$ artigo que publicou em Le mouvement social (1985), sobre os panoramas como fenômeno social, ancestrais dos mass-media e como resultados da confluência entre arte e indústria, insere-os numa área de análise complexa, como componentes de uma sociedade na qual se dão os primeiros 
fenômenos de massa, associados aos primeiros aglomerados urbanos, a sociedade industrial.

É nítido que Comment não se sente totalmente à vontade no campo da História da Cultura, buscando seus referenciais sempre numa certa História da Arte stricto sensu. Tanto é assim que no capítulo que dedica à questão do público, a qual não poderia deixar de abordar ("Quel public?", p. 79-83), busca reforço no artigo de Robichon citado acima. Mesmo assim, a obra de Comment adentra sinuosamente a História da Cultura, embora evitando um mergulho mais profundo nesta área. Outra lacuna - que, aliás, é percebida em todas as obras gerais sobre os panoramas - é a menção a vários outros tipos de sistemas a eles contemporâneos (variações para fins semelhantes), sem contudo explicar cada um deles. No capítulo "Variations: du diorama au 'moving panorama" ",Comment cita quatorze tipos diferentes de espetáculos ópticos, explicando, porém, apenas onze deles. Ficam sem qualquer explicação os citados alporama, o georama e também as fantasmagorias (estas últimas, projeções luminosas cuja genealogia e funções sociais podem ser compreendidas pela leitura de Jacques Perriault - 19811.

Outro ponto questionável é a forma como Comment dissocia panoramas e dioramas, dizendo que "malgré les rapprochements effectués par la plupart des commentateurs ou des historiens, on se rend compte que le diorama a peu à voir avec le panorama. "I n'en est même pas à proprement parler un derivé" (p. 33). As diferenças apontadas pelo autor residem nas dimensões (muito menores nos dioramas), no enquadramento (que se procura eliminar nos panoramas), na ausência de uma visão totalizante no diorama e, num ponto principal, o jogo que se faz no diorama com o movimento e a duração, representando-se, frequentemente, fenômenos da natureza, como passagens do dia para a noite, de uma estação climática para outra ou ocorrências de catástrofes naturais.

É bastante meritório o estabelecimento deste tipo de diferenciação, especialmente no tocante aos espetáculos de transformação mencionados, que quase não se fez anteriormente. Entretanto, a simples existência dessas diferenças não justifica uma dissociação entre dioramas e panoramas.

Parece-nos que a essência dos dois sistemas é a mesma: uma cena pintada, atravessada por luzes de maior ou menor intensidade, visando proporcionar um espetáculo óptico ilusionista. A propósito, o próprio Comment mostra que Daguerre, antes de inventar o diorama, colaborou com Prévost lum dos pioneiros franceses) na realização de vários panoramas (p. 30). Este fato, por si só, é já forte indício de que o diorama deriva, sim, do panorama. E o próprio Daguerre - que entre outras atividades dedicou-se à cenografia teatral foi também o introdutor de elementos tridimensionais, que, conjugados às pinturas panorâmicas, concorrem para efeitos de ilusão, procedimento que viria a ser popularmente consagrado na segunda metade do século XIX, sob protestos dos puristas (cf. Robichon 1982: 107 e ss.).

As exposições universais merecem um ítem específico na obra de Comment (p. 43-47), em razão do élan que deram aos panoramas no final do século XIX: a de 1889 os "ressuscita", após um período de relativo abandono, 
e a de 1900 figura como seu "canto do cisne", ambas realizadas em Paris. Este fenômeno havia já sido apontado, também por Robichon (1982).

Comment apenas elenca e descreve em breves linhas os panoramas exibidos nestas ocasiões. Em 1889 aponta a instalação de pelo menos sete panoramas, mas não se detém em todos eles e nem esclarece que a maior parte não pertencia propriamente à Exposição Universal, embora se beneficiasse, evidentemente, da grande massa de público presente em Paris naquela ocasião. Um desses panoramas (e que não é tratado por Comment), pode interessar mais de perto os brasileiros: trata-se de uma vista da Baía de Guanabara, pintada por Vitor Meireles - ou "Mérelle", como foi erronea e freqüentemente grafado em obras estrangeiras o nome do pintor brasileiro - e o belga langerock. (Anteriormente, em 1824, um outro panorama do Rio de Janeiro, pintado por G.P. Ronmy, havia sido mostrado em Paris e é objeto do artigo de Margareth Campos da Silva Pereira, neste mesmo número dos Anais do Museu Paulistal.

Limitando-se a assinalar a importância das Exposições Universais no que representam como afluxo de público para os panoramas, Comment, assim como Robichon e os demais não atenta para relações mais íntimas que se podem estabelecer entre umas e outros. Sobre relações de sentido entre panoramas, visão panorâmica e exposições universais, como fenômenos de representação num mundo em transformação pela ciência e tecnologia, veja-se Heloisa Barbuy (1995). Na Exposição Universal de 1889 pode-se perceber uma tendência à retomada da sinestesia (conduzida pela visão), que viria se comprovar em 1900, com o famoso mareorama e com outros tantos espetáculos do gênero. O mareorama, tratado por Robichon (1982: 112) e por Comment (p. 45 e p. 70), pretendia ser um espetáculo multi-sensorial, em que à pintura panorâmica associavam-se movimentos, ventilações e odores, o que faz com que Comment o defina, na mesma linha dos próprios cronistas de 1900, como um "espetáculo total".

Passemos, então, aos pontos discutidos por Comment na parte das "Questions théoriques", sistematizadas pelo autor com muita propriedade. Bernard Comment discute a genealogia dos panoramas, pondo em questão certas relações de "parentesco" normalmente aceitas. A primeira delas é com as cúpulas barrocas, algumas vezes apontadas como panoramas avant la lettre e cuja aproximação com os panoramas propriamente ditos, o autor considera indevidos. Isto porque, segundo ele, "le baroque et sa perspective sott'in sù, par exemple, implique avant tout une soumission au pouvoir divin, alors que la perspective circulaire s'assimile davantage à une prise de possession de la nature par l'homme" (p. 51). Mas um interessante e pouco citado artigo, assinado por Patrice Thompson (1982) parece-nos mais convincente em seus argumentos em sentido contrário, mais baseados na análise da experiência visual em si do que nas conotações religiosas ou laicas de que estas pudessem estar revestidas. Menciona, especialmente, O milagre de Santo Antonio, em San Antonio de la Florida, em Madri, como um exemplo nítido de encerramento do observador dentro de um espaço, com seu campo de visão coincidindo com o espetáculo apresentado. $O$ espetáculo é apresentado por efeitos de difusão de luz sobre uma pintura, captados pela visão de um espectador que se move 
sob a cúpula, aparentemente livre mas dentro dos limites que the são obrigatórios.

P. Thompson publicou este artigo em um número da revista Romantisme, dedicado ao espetáculo romântico. Vendo o panorama sob este prisma, produziu uma das melhores análises existentes sobre o panorama enquanto experiência óptica vivida pelo observador.

Quanto à relação entre panoramas e vedute (ou vues d'optique), Comment diminui igualmente sua importância, argumentando que, por mais que alarguem a visão pelo próprio alongamento horizontal das telas, não chegam a romper com a lógica do quadro, tarefa que estaria reservada aos panoramas, também conhecidos como "quadros sem bordas". (Sobre as vedute, ver Minici 1988).

Comment prefere situar as origens dos panoramas nas linhas de pensamento filosófico de Diderot, assim como de locke e Hume, fundadoras de uma nova estética e, dentro desta, da busca do sublime. O sublime seria marcado pela emoção provocada pelo terror, tal como poderia ser desencadeada pela visão de um abismo, do infinito, da vastidão de um panorama. Essas considerações são bastante pertinentes e muito valiosas como contribuição nova mas não vemos porque devam se sobrepor às já usuais análises que buscam as prefigurações dos panoramas nas experiências ópticas anteriores, mais do que em linhas filosóficas de pensamento.

Além desta raiz filosófica, Comment aponta para as práticas cartográficas que se desenvolviam desde o século XVIII como antecessoras dos panoramas, envolvendo preocupações artísticas e científicas ao mesmo tempo, em suas representações topográficas. Ainda assim, embora claramente relacionadas com os panoramas pelo modo como eram captadas as paisagens (um observador postado no topo de uma montanha ou de uma torre, com uma paisagem em torno de sil, não vemos porque serem consideradas mais próximas destes do que as vedute ou as cúpulas barrocas.

Mais uma vez o que está em questão é a importância que o autor confere às teorias estéticas e às questões de composição artística, em detrimento da situação empírica a analisar, isto é, o ponto de vista do observador do espetáculo denominado "panorama".

Mas, talvez justamente por sobrepor a função racional à experiência óptica, um ponto muito bem colocado por Comment é a questão da ilusão e de seus limites. Os testemunhos que nos ficaram da experiência de alguns dos primeiros espectadores dos panoramas levam a crer, em sua maioria, que a ilusão pudesse ser realmente completa e por isto seguida, até mesmo, de reações nervosas e multi-sensoriais (cf. Comment: 68). Mas esta idéia de ilusão perfeita será resultado dos panoramas, diretamente, ou da literatura que os acompanha? Quem conta um conto aumenta um ponto e talvez a predisposição à ilusão tenha colaborado para a produção de tais testemunhos. $O$ observador é, na verdade, um componente de toda a instalação do panorama, uma vez que se coloca até mesmo dentro dela, da rotunda. Pressupõe-se um jogo com o observador, ao qual Comment denominou "jogo do imaginário" (p. 70). Conta-se, então, com o imaginário do observador para a produção da ilusão. $O$ relato sobre o panorama das montanhas suíças transcrito por Comment é um bom exemplo desta ação do imaginário e de sua transposição para a literatura: 
"Dans le lointain horizon clair et dévoilé se dressent les régions enneigés de la Suisse. (...) On entend gronder le tonnerre au loin, on sent le premier tremblement de la foudre qui s'approche: on voudrait s'enfouir sous les tours du château toutes proches avant que n'éclate l'orage menaçant" (p. 72).

O objetivo era a ilusão total e por isto a qualidade dos panoramas era medida por sua capacidade de provocar maior ou menor grau de ilusão. Comment recupera alguns relatos que apontam para os impecilhos à ilusão completa, tais como a ausência de movimento e a temporalidade fixa de uma cena.

A distância fixa e intransponível em que se coloca o observador diz respeito, também, à ilusão, na medida que é necessária para que este tenha a impressão do conjunto - a visão panorâmica - e não se aperceba dos detalhes prosaicos de confecção da pintura. A "lógica perspectiva", como bem define Comment (p. 74) preside o sistema de observação dos panoramas. Segundo ele, com os panoramas, "pour la première fois dans I'histoire de la représentation mimétique (...) le spectateur est assigné à distance fixe et intransgressable" (p. 76). E isto em favor, é claro, do efeito de ilusão. A observação dos detalhes é contrária à ilusão e, neste sentido, Robichon (1982) comenta, relativamente aos panoramas de batalhas, o excesso de detalhes dos panoramas alemães, que atrapalhariam o perfazimento da ilusão.

Ter Jerusalém, Londres, Rio de Janeiro ou, ainda, a batalha de Solferino diante de si, facilmente: Comment (p. 84-88) trata a questão como sendo de "constituição de memória" (conhecer paisagens e situações pela mediação do panorama) ou de "experiência substituída" (ver ou rever paisagens e situações, tomando o panorama como garantia de verdade, de realidadel, uma vez que se valorizava, freqüentemente, na publicidade, o fato de que o pintor tivesse estado no local representado e o tivesse reproduzido fidedignamente.

Outro ponto interessante, abordado por Comment, é a idéia da viagem de consumo burguês, isto é, um deslocamento cômodo, sem riscos, sem sair de sua própria cidade. Jerusalém, por exemplo, torna-se mais um bem de consumo à disposição de todos, em troca de algumas moedas e sem os inconvenientes das viagens comuns.

A questão central, entretanto, é a do simulacro:

"l'expérience du monde et de la réalité est remplacée par leur simulacre" (p. 87).

O simulacro é, a nosso ver, em suas diversas manifestações desde o final do século XVIII, um mecanismo de experimentação do mundo mas, também, de compreensão deste mundo $e$, ainda, de projeção de novas realidades a construir. Não se trataria, então, apenas da substituição da experiência real pela do simulacro mas da compreensão deste real, sintetizado e simplificado no simulacro ou, ainda, de uma projeção de outro real, através do simulacro (cf. Barbuy 1995: 123-131).

Por isto mostram-se, também, panoramas de certas cidades dentro das próprias cidades que eles representam (Comment, p. 89-94). E todo o 
fenômeno está ligado ao fato de que o período que se vivia era de intensas e desnorteadoras transformações. Vai nesta linha a interpretação de Comment: as amplas mudanças por que passa o espaço público provocam uma perda de referência e a conseqüente necessidade de compreender o novo. $E$ isto pode ser feito através de uma síntese, o panorama:

"... (le publicl vient vivre l'illusion bien plus précieuse d'une maitrise sur le monde, sur l'espace collectif; dans le panorama, la ville se donne comme une configuration stable ordonnée autour du spectateur qui se réapproprie ainsi l'agglomération dans laquelle il éprouve quotidiennement limpression de se perdre" (p. 91 ).

\section{BIBLIOGRAFIA CITADA:}

BARBUY, Heloisa. A Exposição Universal de 1889: visão e representação na sociedade industrial. São Paulo, 1995. 170p. Dissertação (Mestrado) - Faculdade de Filosofia, Letras e Ciências Humanas, Universidade de São Paulo.

BAUDRILLARD, Jean. Simulacre et simulation. Paris: Galilée, 1981.

BORDINI, Silvia. Arte, imitazione, illusione: documenti e note sulla pittura dei panorami (17871910). Roma: Quasar, 1981.

Storia del panorama: la visione totale nella pittura del XIX secolo. Roma: Officina, 1984.

BUDDEMEIER, Heinz. Panorama, Diorama, Photographie: Entstehung und Wirkung neuer Medien im 19. Jahrhunderts. Munich: Wilhelm Fink Verlag, 1970.

CRARY, Jonnathan. Techniques of the observer: on vision and modernity in the nineteenth century. London: October Books, 1990.

DAS PANORAMA. Zeitschrift für Schweizerische Arcbäologie und Kunstgescbichte, n. 4. p. 241$344,1985$.

HYDE, Ralph, org. Panoramania! The art and entertainment of the "all-embracing" view. London: Trefoil Publications/ Barbican Art Gallery, 1988.

KUNST-UND-AUSSTELLUNGSHALLE DER BUNDESREPUBLIK DEUTSCHLAND. Sebsucht: Das Panorama als Massenunterhaltung des 19. Jahrhunderts. Basel-Frankfurt: Stroemfeld/Roter Stern, 1993.

LE MEN, Segolène. Lanternes magiques: tableaux transparents. Paris: Musée d'Orsay/Réunion des musées nationaux, 1995. (Catálogo de exposiçâo).

MINICI, Carlo Alberto Zotti, org. Il mondo nuovo: le meraviglie della visione dal ' 700 alla nascita del cinema. Milano: Mazzotta, 1988. 
NOUVEL-KAMMER, Odile, org. Papiers peints panoramiques. Paris: Flammarion, 1990.

OETTERMAN, Stephan. Das Panorama: Die Geschichte eines Massenmediums. Frankfurt: Syndicat, 1980.

PANORAMAS - photographies 1850-1950, Collection Bonnemaison. Arles: Actes Sud/Afirmatif/Rencontres internationales de la photographie, 1989.

PEREIRA, Margareth da Silva. Romantismo e objetividade: o primeiro panorama do Rio de Janeiro. Anais do Museu Paulista, Nova série-v.2, 1994.

PERRIAUlT, Jacques. Mémoires de l'ombre et du son: une archéologie de l'audiovisuel. Paris: Flammarion, 1981.

ROBICHON, François. Les panoramas en France au XIXe siècle. Paris/Nanterre, 1982. Tese (Doutoramento de 3o. ciclo) - Universidade de Paris X-Nanterre. 3v.

Le panorama, spectacle de l'histoire. Le mouvement social, n. 131 , p. $65-86$, avr.-juin 1985.

THOMPSON, Patrice. Essai d'analyse des conditions du spectacle dans le panorama et le diorama. Romantisme: revue du dix-neuvième siècle, n. 38, p. 47-64, 1982. 